\title{
Review of Electromagnetic failure, optimization techniques and stress prediction in Interconnect
}

\author{
Arti Joshi, Rishika Sethi, Purushottam Kumawat \\ Research Scholar, Poornima University Ramchandrapura, Vidhani,Sitapura, india
}

\begin{abstract}
The ever increasing demand of digital computing and wireless communication have been driving the semiconductor technology to change with passing days. Modern electronics system integrates more complex component and devices, which result in a very complex electromagnetic field environment Moore's law has driven the scaling of digital electronic devices, dimensions and performances over the last 40 years. In today's world, there is demand of devices which are faster, better and having less power consumption. Now we need to better optimize the circuit at available technologies. Interconnection used to connect components on a VLSI chip, chips on a multichip module and to connect multichip modules on a system board. Most of the chips are covered by Interconnects. On-chip interconnects which was considered only as a parasitic load before 1990s became the real performance bottleneck due to its extremely reduced cross section dimension [31]. Today, onchip global interconnect with conventional $\mathrm{Cu} / \mathrm{low}-\mathrm{k}$ and delay optimized repeater scheme faces great challenges in the nanometer regime, imposing problems of slower delay, higher power dissipation and limited bandwidth.
\end{abstract}

Key words: On chip interconnect, low-k dielectric, stress prediction

\section{INTRODUCTION}

The ever decreasing interconnects cross section dimensions give rise to increase in resistance. In addition, surface and grain-boundary scattering of electrons in $\mathrm{Cu}$ becomes a serious problem as the wire size becomes almost comparable to the grain size of $\mathrm{Cu}$. Eventually leading to higher resistivity than bulk $\mathrm{Cu}$. Putting all these together, degradation of the RC time constant of on-chip metal wires becomes more serious. As a consequence, the continuous performance degradation of on-chip Cu/low $\mathrm{k}$ interconnects is one of the greatest challenges to maintain Moore's law alive while the scaling of transistors" dimension has provided relentless delay improvement. The scaling of interconnects dimension deteriorates not only delay time, but also all related interconnect performance metrics, such as power dissipation, reliability, and bandwidth, for local, semi-global and global levels. The on-chip power dissipation problem is coupled with an increasing number of repeaters to alleviate long $\mathrm{RC}$ time constant of $\mathrm{Cu}$ wire, switching activity factor, an increase of operating frequency.

\section{REVIEW PROCESS ADOPTED}

The review process is divided into five stages in order to make the process simple and adaptable by every researcher. As it reflects from the literature that while beginning the finding of research objectives, it is necessary to start with a broader domain of any area / sub area of interest and narrow down to the specific issue, the process described in the diagram includes the narrowing down. We have followed one of the typical processes to make a literature review and frame the objectives of the research. The process diagram is shown in Fig. 1, which includes all five stages defined as below:

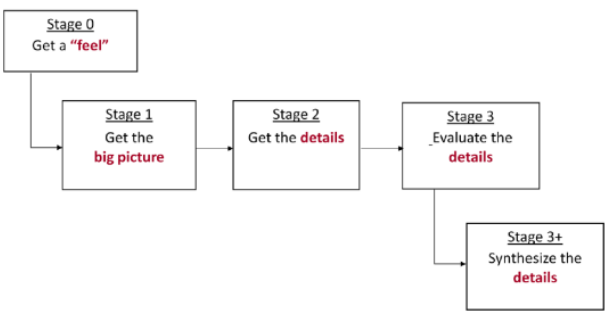

Stage 0: Get the Feel

Fig1: Literature Review Process

Stage 1: Get the Big Picture

Stage 2: Get the Details

Stage 3: Evaluate the Details

Stage $3+$ : Synthesize the Details. 


\section{METHODOLOGIES/SOLUTION APPROACHES}

After reviewing the 30 research papers we categories the review in four major issues

(1) Interconnection properties

(2) Design optimization

(3) Interconnect material

(4) Interconnection technology

\section{Findings Of Interconnection Properties}

- Two failure modes (2D \& 3D Agglomeration) are induced by thermal stress in $140 \mathrm{~nm} \mathrm{Cu}$ interconnects which leads to low yield \& structure change.

- Two kinds of test patterns, Electrical \& EXAFS Analysis has done [6].

- Mechanical stresses in metal interconnects cause void formation or metal extrusion into the passivation which leads to failure.

- A numerical solution scheme has been implemented to calculate the atomic fluxes and the evolution of mechanical stress in interconnects.

- Simulation runs were performed using the developed numerical scheme using MathCAD. Stress calculations were simulated for units with known geometry, Electro migration stress conditions and TTF [12].

- Degenerated Exhaustive Direct Charge Measurements (DEDCM) method is used to measure the interconnect capacitance [21].

\section{Findings Of Design Optimization}

- Optimized Spin-on-Glass processes and a thin layer of CVD silicon dioxide and a curing temperature below the sintering temperature of the metal interconnect layer produced less cracking, no gaps, and smooth features.

- It is able to planarize the surface smoothly without any cracks [5].

- Scheduling Algorithm uses segmented buses to minimize area and energy consumption in interconnect design without performance degradation.

- Dynamic energy consumption can be reduced by about $71 \%$ and static energy consumption by about $35 \%$ on average when the proposed algorithm is compared with the existing communication cost-conscious scheduling techniques [21].

- Partial Element equivalent circuit model efficiently verifies the signal integrity of highly complex nano scale based interconnect structure.

- It can be used as an indicator for predicting the level of deterioration in the system performance [20].

\section{Findings Of Interconnect Material}

- Near Noble Metal Silicides Nisi2 can serve for first level metallization on planar surfaces.

- It shows low resistivity, high current capability \& long term stability [1].

- MWCNT/Nano composite $\mathrm{Cu}$ films produced by a low cost \& low temperature electrochemical method.

- MWCNT content in the film is varied by $\mathrm{Cu}$ grain size \& CNT Concentration in the electrolyte.

- MWCNT shows enhanced mechanical properties \& dense structure without voids [14].

- Liquid metal interconnect used to produce the flexible skin sensor to be used in robots.

- The liquid metal interconnect is better to develop the super flexible skin sensors than the solid metal interconnect in terms of robustness \& Flexibility [10].

\section{FINDINGS OF INTERCONNECTION TECHNOLOGY}

- Advanced ALIVH Interconnection technology has improved features like low moisture uptake, High Tg, Low CTE \& high elastic modulus.

- In this technology, new functional materials have been used \& electric interconnections were computed by controlling thickness \& viscosity of resin [7].

- ACF interconnection technology is used in flexible electronics to improve the efficiency of flat panel display and the requirement of fine pitch capability.

- It controls the volume fraction of conducting particles into the adhesive film \& the problem of larger size and bad resolution quality of flexible electronics has improved [11].

- The Optical interconnection technology is used to improve the efficiency, densities and speed performance of IC.

- It provides better results than the metal interconnection technology in terms of improvement in the overall performance of IC. Planar Interconnects Technology overcomes the electrical performance of Al wire bonding such as in the terms of on-resistance and stray inductance by replacing $\mathrm{Al}$ wire bonds with $\mathrm{Cu}$ wire bonds [3]. 
- CMP Process can be used to accommodate the higher degree of process control required in the finer geometry or dual inlaid structures.

- It provides better oxide erosion control for the finer geometry \& multiple level structures [29].

- Space Division Multiplexed Microstructure optical fiber bus to be used for a chip to chip optical interconnects (C2OIs) [24].

- Multicore MFs featured several solid cores surrounded by a cladding region, was modeled using a Finite difference BPM Algorithm. Novel copper ball interconnection technology for $60 \mathrm{GHz}$ band 3-D Systemin-Package ( $\mathrm{SiP}$ ) modules using organic substrates, used for providing interconnections between substrates. Two balls are used for signal line connection \& eight balls are used for ground connection [24].

- Photonics-Electronics Convergence system was used to solve the B.W. Bottleneck problem in inter-chip interconnects.

- This system enables us to replace the function of conventional electronic wires on a printed circuit board (PCB) with the optical interconnects on a silicon substrate with error free data transmission at $12.5 \mathrm{Gbps}$ NRZ [25].

- The solder joint based flip chip interconnection technology has strong potential in terms of its high electrical and mechanical performance and its low manufacturing cost.

- It is used for fine pitch (100 micrometers) and high density requirement [9].

- The T-G2BGA (Tape Gold-Gold gang bond BGA) has a low cost, highly reliable CSP (Chip Size Package) for compactness, and light memory device package to be used in mobile computers and cellular phones for large data storage.

- The parameters in T-G2BGA technology are bump shape, substrate pad surface plating specification, and flip chip bonding conditions [4].

- Photonic technologies are used to relieve the increasing power consumption for the ICT (Information and communication Technology) system.

- The Optical-component technologies, which include LDs, PDs, drivers, and TIAs, are key factors in realizing a high-speed, compact, and low-power 100GbE interface [18]

- VCI technology has introduced to reduce the package size or to enhance the electrical performance of stacked die packages.

- The key processes of VCI technology are coating, laser ablation and conductive glue which have used after die attach, to replace traditional wire bonding technology [19].

VIII. Issue Wise Solution Approaches

\begin{tabular}{|c|c|}
\hline \multicolumn{2}{|c|}{ Interconnection properties } \\
\hline Solutions & Strength \\
\hline Math CAD Simulator Tool & $\begin{array}{l}\text { It measures Line Stress at Total } \\
\text { Time Failure (TTF) [12]. }\end{array}$ \\
\hline $\begin{array}{l}\text { Power/Thermal Management } \\
\text { Algorithm. }\end{array}$ & $\begin{array}{l}\text { Significant improvements in } \\
\text { reliability [27] }\end{array}$ \\
\hline DEDCM method. & $\begin{array}{l}\text { Obtain complete capacitance } \\
\text { information of interconnect } \\
\text { network more accurately and faster } \\
{[21]}\end{array}$ \\
\hline $\begin{array}{l}\text { Lead-free solders with a low Ag- } \\
\text { content }\end{array}$ & Stress reduction [17]. \\
\hline $\begin{array}{l}\text { Collinear Transition Differential } \\
\text { Scanning Calorimetry (DSC). }\end{array}$ & $\begin{array}{l}\text { Large Bandwidth and wide range of } \\
\text { coupling coefficient [2]. }\end{array}$ \\
\hline Dynamic Reliability Model. & Explore the design space [28] \\
\hline \multicolumn{2}{|c|}{ Interconnection Materials } \\
\hline $\begin{array}{l}\text { Multi Walled CNT / } \\
\text { Nanocrystalline Copper Film. }\end{array}$ & $\begin{array}{l}\text { 1. Cu films show dense structure } \\
\text { (without any voids) } \\
\text { 2. Enhanced Mechanical properties } \\
\text { [14]. }\end{array}$ \\
\hline Liquid Metal interconnect & Robustness and flexibility [10]. \\
\hline Near Noble Metal Silicides & $\begin{array}{l}\text { 1. High oxidation rate } \\
\text { 2. Low resistivity } \\
\text { 3. Low formation temperature of } \mathrm{Ni} \\
\text { rich phase } \\
\text { 4. Provides High current capability } \\
\text { 5. Long term stability } \\
\text { 6. Metallization level increases [1] }\end{array}$ \\
\hline \multicolumn{2}{|c|}{ Design Optimization in Interconnects } \\
\hline Optimized Spin on Glass Process. & $\begin{array}{l}\text { Less cracking, no gaps, and smooth } \\
\text { features in multilevel interconnect } \\
\text { layers [5]. }\end{array}$ \\
\hline Scheduling Algorith & Dynamic e \\
\hline
\end{tabular}




\begin{tabular}{|c|c|}
\hline & $\begin{array}{l}\text { be reduced by about } 71 \% \text { and static } \\
\text { energy consumption by about } 35 \% \\
{[20]}\end{array}$ \\
\hline $\begin{array}{l}\text { Partial Element Equivalent } \\
\text { Circuit Model. }\end{array}$ & $\begin{array}{l}\text { Computing the stress evaluation in } \\
\text { the line [23] }\end{array}$ \\
\hline \multicolumn{2}{|c|}{$\begin{array}{l}\text { Interconnection Technology } \\
\end{array}$} \\
\hline $\begin{array}{l}\text { Sand Blasting \& Laser Filling } \\
\text { Method. }\end{array}$ & $\begin{array}{l}\text { Smaller size circuits with high } \\
\text { electrical performance \& reliability } \\
\text { [13] }\end{array}$ \\
\hline $\begin{array}{l}\text { Advanced ALIVH } \\
\text { Interconnection Technology }\end{array}$ & $\begin{array}{l}\text { A short wire length between } \\
\text { substrate and via hole shape } \\
\text { remains preserved [7]. }\end{array}$ \\
\hline $\begin{array}{l}\text { Anisotropic Conductive Films in } \\
\text { Flexible Electronics. }\end{array}$ & $\begin{array}{l}\text { Avoids the problem of larger size } \\
\text { and bad resolution quality of } \\
\text { flexible electronics [11]. }\end{array}$ \\
\hline $\begin{array}{l}\text { T-G2BGA Interconnection } \\
\text { Technology }\end{array}$ & $\begin{array}{l}\text { Low cost, highly reliable CSP } \\
\text { (Chip Size Package) for } \\
\text { compactness, and light memory } \\
\text { devices package [4] }\end{array}$ \\
\hline Metal \& Optical Interconnection & Improves overall performance [3]. \\
\hline Planar Interconnects Technology. & $\begin{array}{l}\mathrm{R}_{\text {th }} \text { reduces to } 0.69 \mathrm{~K} / \mathrm{W} \text { to } 0.55 \mathrm{~K} / \mathrm{W} \\
\text { (approx } 20 \% \text { ) [22] }\end{array}$ \\
\hline G-Helix Low-K Interconnects & $\begin{array}{l}\text { Fabrication of the interconnects at } \\
100 \text { um pitch [15]. }\end{array}$ \\
\hline CMP Process & $\begin{array}{l}\text { It provides better oxide erosion } \\
\text { control for the finer geometry \& } \\
\text { multiple level structures [29]. }\end{array}$ \\
\hline $\begin{array}{l}\text { Space Division Multiplexed } \\
\text { Micro structured optical fiber bus }\end{array}$ & $\begin{array}{l}\text { Micro structured optical fiber bus } \\
\text { low cross talk \& low bend loss [24] }\end{array}$ \\
\hline $\begin{array}{l}\text { Copper balls interconnection } \\
\text { technology }\end{array}$ & $\begin{array}{l}\text { Improves the Transmission } \\
\text { Characteristics of interconnects } \\
\text { simultaneously providing low cost } \\
\text { \& keeping flat \& stable spaces v/w } \\
\text { substrates [16]. }\end{array}$ \\
\hline $\begin{array}{l}\text { Photonics-Electronics } \\
\text { Convergence system }\end{array}$ & $\begin{array}{c}\text { Error Free Data Transmission in } \\
\text { inter-chip Interconnects [25] }\end{array}$ \\
\hline VCI Technology & Reduce the package size [19] \\
\hline $\begin{array}{l}\text { CNT Array as High Impedance } \\
\text { Interconnects. }\end{array}$ & $\begin{array}{l}\text { Radiative heating mode technique } \\
\text { keeps the substrate temperature, } \\
\text { low [26]. }\end{array}$ \\
\hline
\end{tabular}

\section{Common Findings}

- Out of 30 Research Papers which we reviewed, we found 4 Main issues.

- First Issue is Interconnects Materials, The Best Approach used in this issue is Near Noble Metal Silicides (NiSi2) as it provides low resistivity, high critical current density \& long term stability of interconnect lines While the approach Multi walled CNT/ Nano Crystalline Cu Film is not so good as in this technology the thermal conductive of interconnects drastically decreases.

- The Second Issue is Design Optimization of Interconnects. The Best Approach used in this issue is Scheduling Algorithm as this approach minimizes the interconnection's dynamic energy consumption by $71 \%$ and static energy consumption by about $35 \%$ without performance degradation. While the approach Partial Element Equivalent Circuit Model is very complex.

\begin{tabular}{|c|c|c|}
\hline Technology & Limitation & Scope of work \\
\hline $\begin{array}{l}\text { Near Noble } \\
\text { Metal } \\
\text { Silicides }\end{array}$ & $\begin{array}{l}\text { Surface roughness caused } \\
\text { by micro cracks \& broken } \\
\text { steps after high temperature } \\
\text { metal layer formation [1] }\end{array}$ & $\begin{array}{l}\mathrm{Nisi}_{2} \text { along with the } \\
\text { refractory metal silicide } \\
\text { i.e. } \mathrm{TiSi}_{2} \& \mathrm{WSi}_{2} \\
\mathrm{Nisi}_{2} \text { along with the } \\
\text { refractory metal silicide } \\
\text { i.e. } \mathrm{TiSi}_{2} \& \mathrm{WSi}_{2}\end{array}$ \\
\hline MWCNT & $\begin{array}{l}\text { Thermal conductivities } \\
\text { were drastically decreased } \\
\text { \& Resistivity Increases } \\
{[14]}\end{array}$ & $\begin{array}{l}\text { New additives in order } \\
\text { to enhance the thermal } \\
\& \text { electrical }\end{array}$ \\
\hline $\begin{array}{l}\text { Metal } \\
\text { interconnect } \\
\text { technology }\end{array}$ & $\begin{array}{l}\text { Degrades the performance } \\
\text { of IC [5]. }\end{array}$ & $\begin{array}{l}\text { A combination of metal } \\
\text { and optical } \\
\text { interconnects to } \\
\text { improve the overall } \\
\text { performance of the } \\
\text { chips. }\end{array}$ \\
\hline
\end{tabular}




\begin{tabular}{|l|l|l|}
\hline $\begin{array}{l}\text { Dynamic } \\
\text { Reliable } \\
\text { model }\end{array}$ & $\begin{array}{l}\text { Not suitable to Compare } \\
\text { model Prediction with } \\
\text { Experimental data [28] }\end{array}$ & $\begin{array}{l}\text { Further modified by } \\
\text { considering other } \\
\text { failure mechanisms } \\
\text { such as fast thermal } \\
\text { cycling, stress- } \\
\text { migration }\end{array}$ \\
\hline $\begin{array}{l}\text { Low k } \\
\text { dielectric }\end{array}$ & $\begin{array}{l}\text { The fabrication process is } \\
\text { not cost competitive [15] }\end{array}$ & $\begin{array}{l}\text { Number of masking } \\
\text { steps should be reduced }\end{array}$ \\
\hline $\begin{array}{l}\text { Wire bond } \\
\text { technology }\end{array}$ & $\begin{array}{l}\text { Increase the size of } \\
\text { package body with respect } \\
\text { to the number of dice } \\
\text { stacked in the package [19] }\end{array}$ & Optical interconnect \\
\hline
\end{tabular}

\section{Conclusion}

Hereafter finding the solution approaches, we concluded that Interconnect Technology is the main area into which the future work can be done. We found 15 Solution approaches out of which Advanced ALIVH Interconnection Technology, CMP Process, Planar Technology, Photonics-Electronics Convergence system \& G-Helix Low-K Interconnects are most promising due to their advantages \& properties. The exhaustive review could finally lead to extract findings in the area, strengths and weaknesses and scope of work during M. Tech thesis.

\section{Acknowledgments}

We would like to express our deep gratitude and thanks to Prof. Mahesh Bundele, Coordinator, Research for giving us an opportunity to work under his guidance for review of research papers and his consistent motivation \& direction in this regard. We would also express our sincere thanks to Mr. Devendra Kumar Somwanshi, Associate Professor, M Tech, Poornima University for their guidance and support.

\section{References}

[1] M. Bartur and M.A. Nicolet, "Utilization of Nisi, as an Interconnect Material for VLSI", IEEE, 1984.

[2] Hung-Yu Yang and Nicolaos G. Alexopoulos, "Basic Blocks for High-Frequency Interconnects: Theory and Experiment" IEEE Transactions on Microwave Theory and Techniques, Vol. 36, No. 8, August 1988.

[3] D. Jiang, B. L. Bhuva, D. V. Kerns, Jr., and S. E. Kerns "Comparative Analysis of Metal and Optical Interconnect Technology" 07803-6327-2/00/\$10.00 02000 IEEE.

[4] Seiya Isozaki, Takehiro Kimura"Development of Low Cost, Highly Reliable CSP using Gold-Gold Interconnection Technology" 2001 Electronic Components and Technology Conference.

[5] Aric C. Madayag and Zhiping Zhou "Optimization of Spin-On-Glass Process for Multilevel Metal Interconnects" 0-7803-66913/01/\$10.00 02001 IEEE

[6] Norio Okada, Yoshihisa Matsubam, Hidekazu Kimura, Hirokazu Aizawa, Norio Nakamura Junoh Park, Byoungchul Ko, Jae-Yeal Nam, Sooyeong Kwak, "Thermal Stress of 14Onm-width Cu damascene interconnects", 2002.

[7] Shozo Ochi, Fumio Echigo, Tadashi Nakamura, Yoshihiro Tomita, Daizo Andoh,"A Study of Advanced ALIVH Interconnection Technology",8th international Symposium on Advanced Packaging Materials, 2002.

[8] David L. Young, Miguel Contreras, Manuel Romero, Sally Asher "Interconnect Junctions For Thin-Film Tandem Solar Cells", 3rd World Conference On Photovoltaic Energy Conversion May 11-18.2003 Osaka. Japan.

[9] Zhou Wei, Chia Yong Poo“Development of Fine Pitch Solder Joint Interconnection Technology for Flip Chip Assembly" 2005 Electronics Packaging Technology Conference.

[10] Huan Hu, Kashan Shaikh and Chang Liu "Super flexible sensor skin using liquid metal as interconnect" 1-4244-1262-5/07/\$25.00 (C)2007 IEEE .

[11] Kazuya Matsuda and Itsuo Watanabe "Interconnection Technologies of Anisotropic Conductive Films and Their Application to Flexible Electronics" 1-4244-1253-6/07/\$25.00 @2007 IEEE

[12] Rao R. Morusupalli, William D. Nix, Jamshed R. Patel "Comparison of Line stress predictions with measured electro-migration failure times" 1-4244-1171-8/07/\$25.00 @2007 IEEE.

[13] Tae Hoon Kim, Jong Yeol Jeon, Yun Pyo Kwak, Tae Ho Kim, Yun Jung Lim, Jang Ho Park Seog Moon Choi and Sung Yi, “Interconnection Via Technology and Wafer Level Package for Crystal Unit Device”, 33 International Electronics Manufacturing Technology Conference, 2008.

[14] Jung Joon Yoo, Jae Yong Song, Jin Yu, Ho Ki Lyeo, Sungjun Lee, Jun Hee Hahn2 Shozo,"Multi-Walled Carbon Nanotube/Nanocrystalline Copper Nanocomposite Film as an Interconnect Material". Electronic Components and Technology Conference, 2008.

[15] Karan Kacker, student member, IEEE, George c. lo, and Suresh k. Sitaraman, "low-k dielectric compatible wafer-level compliant chip-to-substrate interconnects" IEEE transactions on advanced packaging, vol. 31, no. 1, February 2008.

[16] Satoshi Yoshida, Shoichi Tanifuji, Suguru Kameda "Copper Balls Interconnection Technology for $60 \mathrm{GHz}$ Band 3-D System-inPackage Modules" Proceedings of Asia-Pacific Microwave Conference 2010.

[17] Steffen Wiese, Frank Kraemer, Norbert Betzl, Dietmar Wald“'Interconnection Technologies for Photovoltaic Modules Analysis of technological and mechanical Problems" $11^{\text {th }}$ Int. Conf. on Thermal, Mechanical and Multiphysics Simulation and Experiments in Micro-Electronics and Micro-Systems, EuroSimE 2010.

[18] Shinji Nishimura"Components and Interconnection Technologies for Photonic-Assisted Routers toward Green Networks" IEEE Journal of Selected Topics in Quantum Electronics, Vol. 17, No. 2, March/April 2011.

[19] Ivan Chang, Jensen Tsai, James Chiang"Development for VCI (Vertical Circuit Interconnection) Technology for Stacked Die Package" 2011 13th Electronics Packaging Technology Conference.

[20] Cathy Qun Xu, Chun Jason Xue, Member, IEEE, and Edwin H.M. Sha, "Energy-Efficient Joint Scheduling and Application-Specific Interconnection Design". IEEE transactions on very large scale integration (VLSI) systems, vol. 19, no. 10, October 2011. 
[21] Masaharu Goto, lun Taniguchi and Kenichi Takano "Fast and Accurate Characterization of Interconnect Capacitance Network Using Degenerated Exhaustive Direct Charge Measurements (DEDCM)”, 978-1-4673-1030-7/12/\$31.00 @2011 IEEE.

[22] K. Weidner, M. Kaspar "Planar Interconnect Technology for Power Module System Integration" Corporate Technology, 81739 Munich, N. Seliger, University of Applied Sciences Rosenheim, 83024 Rosenheim, 2012.

[23] HJ Kadim and L.M. Coulibaly "Computation of Cross-coupling for Reliable System Operation" Third International Conference on Emerging Security Technologies 2012.

[24] Véronique François“Millimeter-Bending-Radius Fiber Bus for Optical Interconnects”, 978-1-4673-5063-1/13/\$31.00 @2013 IEEE.

[25] Yutaka Urino, Tsuyoshi Horikawa, Takahiro Nakamura, Yasuhiko Arakawa"High Density Optical Interconnects Integrated with Lasers, Optical Modulators and Photodetectors on a Single Silicon Chip", 978-1-55752-962-6/13/\$31.00 @2013 Optical Society of America.

[26] Dunlin Tan, Chin Chong Yap, David Hee"Carbon Nanotube Array as High Impedance Interconnects for Sensing Device Integration" 2013 Electronic Components \& Technology Conference

[27] Srijita Patra, Degang Chen"Reliability Degradation with Electrical, Thermal and Thermal Gradient Stress in Interconnects", 978-14673-5762-3/13/\$31.00 @2013 IEEE.

[28] Zhijian Lu, Wei Huang, John Lach, Mircea Stan, Kevin Skadron“Interconnect Lifetime Prediction under Dynamic Stress for Reliability-Aware Design".

[29] C. Dang, C. Pettinato, J. Cope, H. Garcia, J. Saravia, J. Farkas, D. Watts, J. Klein“'Interconnect Material and CMP Process Change Effects on Local Interconnect Planarity"

[30] Masahiro Inoue, and Katsuaki Suganuma "Effect of curing conditions on the interconnect properties of isotropic conductive adhesives composed of an epoxy-based binder"

[31] http://purl.stanford.edu/kv550rj8376

"Comparison Study of Future On-Chip Interconnects For High Performance VLSI Applications" 